\title{
Buddhist Healthcare in Philadelphia: An Ethnographic Experiment in Student-Centered, Engaged, and Inclusive Pedagogy
}

\author{
C. Pierce Salguero
}

check for

updates

Citation: Salguero, C. Pierce. 2021. Buddhist Healthcare in Philadelphia: An Ethnographic Experiment in Student-Centered, Engaged, and Inclusive Pedagogy. Religions 12: 420 https://doi.org/10.3390/rel12060420

Academic Editor: Melanie C. Brooks

Received: 14 May 2021

Accepted: 2 June 2021

Published: 8 June 2021

Publisher's Note: MDPI stays neutral with regard to jurisdictional claims in published maps and institutional affiliations.

Copyright: (C) 2021 by the author. Licensee MDPI, Basel, Switzerland. This article is an open access article distributed under the terms and conditions of the Creative Commons Attribution (CC BY) license (https:// creativecommons.org/licenses/by/ $4.0 /)$.
Division of Arts \& Humanities, Penn State University Abington College, Abington, PA 19001, USA; salguero@psu.edu

\begin{abstract}
This essay describes the Jivaka Project, a pedagogical experiment undertaken at a public liberal arts college outside of Philadelphia. A multi-year ethnographic survey of Buddhist healthcare in the greater metropolitan area, this project has come to constitute a major part of my general education course on American Buddhism. As I argue, this project serves as a model for studentcentered, engaged, and inclusive approaches to pedagogy. It is particularly notable for centering the intercultural competency of international and first-generation Asian American students. I discuss how this project was inspired by a bilingual Chinese American student; how it developed into a large-scale effort involving about a hundred students in ethnographic research in Philadelphia's Asian American neighborhoods; how it was a transformational educational experience for a diverse group of participating students; and how in the process it pushed my pedagogy in a more relevant and personally fulfilling direction.
\end{abstract}

Keywords: Buddhism; pedagogy; ethnography; health; student engagement; multimedia

This essay describes the Jivaka Project, a pedagogical experiment undertaken at a public liberal arts college outside of Philadelphia. ${ }^{1}$ A multi-year ethnographic survey of Buddhist healthcare in the greater metropolitan area, this project has come to constitute a major part of my general education course on American Buddhism. As I argue, this project serves as a model for student-centered, engaged, and inclusive approaches to pedagogy. It is particularly notable for centering the intercultural competency of international and first-generation Asian American students. Below, I discuss how this project was inspired by a bilingual Chinese American student; how it developed into a large-scale effort involving about a hundred students in ethnographic research in Philadelphia's Asian American neighborhoods; how it was a transformational educational experience for a diverse group of participating students; and how in the process it pushed my pedagogy in a more relevant and personally fulfilling direction.

\section{An Inspiration for Student-Centered Pedagogy}

I was trained as a historian of medicine, with particular focus on the translation and adaptation of Indian Buddhist healing practices in medieval China (third to tenth century (E). Much of my research and writing has revolved around the analysis of minute philological details in medieval Chinese texts, unpacking the meanings and connotations of individual Chinese characters. While fascinating from the perspective of medical and religious history, and highly relevant to translation studies, this is not a methodology that translates easily to the American undergraduate classroom. Seemingly disconnected from the pressing issues and concerns of contemporary life, it is difficult to arouse enthusiasm for this topic among my students-and, truth be told, even in myself-when teaching my general education classes.

Let me give you some context. Since earning my PhD, I have worked at Penn State University's Abington College, the only public liberal arts college in the greater Philadel- 
phia metropolitan area. Among a number of classes in Asian Studies and history, I have taught introductory courses in Buddhism for many years. We do not have a major in religious studies, but my courses are still well subscribed, primarily by students seeking to simultaneously fulfill general education humanities credits and the university's cultural diversity requirement. ${ }^{2}$

Typically, half of any given class of mine is made up of students of Asian heritage. The most diverse campus within the Penn State public university system, Abington College is a minority-majority institution and also a Asian American and Native American Pacific Islander-Serving Institution. ${ }^{3}$ Approximately $30 \%$ of our student body identifies as Asian. Many of these students are international students, but a significant number come from immigrant families that predominantly live in working-class Asian American neighborhoods in and around Philadelphia.

At Abington College, we consider ourselves to be a laboratory for innovation in culturally responsive education. We have a well-articulated social mission, and a high level of faculty interest in meeting the pedagogical needs of our socioeconomically, culturally, and linguistically diverse student body. There is also an incipient movement toward comprehensive internationalization of the curriculum and campus. ${ }^{4}$ Although initially I was primarily focused on research that would lead to my getting tenure, over the years, the environment in which I have found myself teaching has profoundly influenced my pedagogical approaches. Over the years, I have been increasingly open to being challenged, expanded, and transformed as a teacher. ${ }^{5}$

One moment that was particularly impactful came during the 2012-2013 academic year, when a group of my students were working on a research poster exploring mindfulness in the context of Buddhist approaches to health and healing. The original plan was for them to describe the range of workshops and medical research related to mindfulness that was taking place in and around Philadelphia. However, halfway through the project, one member of the research team, a young Chinese American woman, asked me if the students' poster could also include a section contrasting mindfulness with the healing rituals that her grandmother participated in at a local Chinese Mahayana temple. ${ }^{6}$ I enthusiastically assented, and soon the students were interviewing both the grandmother and the head monk of her temple (Figure 1). The interviews, conducted in Cantonese and translated by the student, contributed a much-needed missing perspective to the research poster.

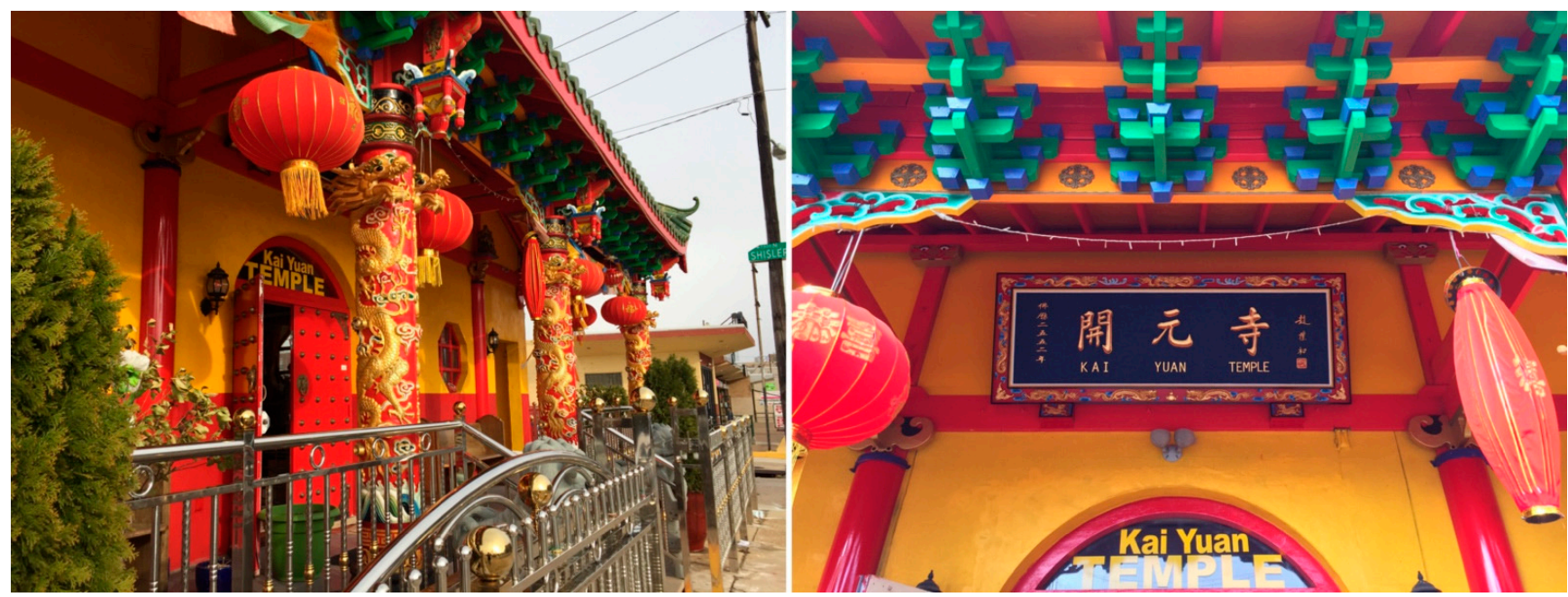

Figure 1. Two views of the façade of Kaiyuan Temple, in northern Philadelphia. Source: www.jivaka.net/philly (accessed on 4 June 2021), Creative Commons license.

A newcomer to the Philadelphia area at the time, I had no connections with any local Buddhist communities. As I have never been part of any Buddhist community or sangha anywhere else in the U.S. either, and did not know much about American Buddhism, I had 
little idea about how many temples there may be in the area. ${ }^{7}$ However, despite my naïveté, I felt that this student was opening my eyes to how the Asian American communities in the city could be incredibly useful partners in teaching students about contemporary Buddhism. I also realized through this interaction that many of our students may already be perfectly positioned to conduct ethnographic research in local temples by virtue of their own heritage, background, or family connections.

In subsequent years, this student's idea to bring her grandmother's temple into conversation with mindfulness would come to have a long-lasting impact on my pedagogy, showing me a way forward to make my courses more relevant, more interesting, and more student-centered than I had previously imagined. As a professor at a relatively small liberal arts institution, I have a lot of latitude to expand my teaching into new territory and to remake myself without stepping on anyone else's toes. So, I spent the next few years getting grounded in the subfield of American Buddhism, reading whatever I could find on the subject and attending relevant panels at the American Academy of Religion's annual conference. ${ }^{8}$ I began designing a syllabus for a new course focusing on American Buddhism that would center the Asian American experience. Simultaneously, I also lined up a few independent study students and we started to search for Buddhist temples around Philadelphia, with an eye towards building an ethnographic component into the new class I was developing. The class eventually launched in 2017.

\section{The Jivaka Project}

Between 2015 and 2020, both independent study students and those in my new class embarked on what came to be called the Jivaka Project (named after Jīvaka Komārabhacca, the Buddha's doctor and a revered figure from Buddhist scripture). ${ }^{9}$ Over this six-year period, about a hundred students conducted participant-observation ethnography at about 45 Buddhist institutions around the greater Philadelphia area. The class ran until spring 2020, when the coronavirus pandemic prevented us from visiting temples and we had to suspend operations mid-semester. It is hoped that we will restart the ethnographic study some time in 2022.

On-site research for the project was undertaken by students in small teams. ${ }^{10}$ Typically, the first step was to conduct a brief site visit to ensure that the location was open, to take photos of the exterior of the building, and to find out when public services were held. Subsequently, teams of students visited the location two to three more times over the course of the six years in order to conduct interviews with monastics, teachers, and community representatives. They also collected photos and audiovisual recordings of interviews, ceremonies, healing activities, and public events. Over the course of these multiple visits, students collected a trove of information about ritual practice, material culture, member demographics, and many other aspects of Buddhism as a lived religion in the local context. However, in line with my own research priorities as a scholar of Buddhism and medicine, the Jivaka Project primarily focused on exploring how Buddhist institutions, practices, and attitudes were contributing to the healthcare landscape of greater Philadelphia.

A good portion of the information and the multimedia materials that students collected has now been synthesized and made public through the project website (www.jivaka. net/philly). The temples are geographically mapped and searchable by category, keywords, and tags. Our audio recordings have also been donated to the American Religious Sounds Project. ${ }^{11}$ In the final two years of the project, I collaborated with documentary filmmaker and medical historian Lan A. Li to produce six short films about various aspects of local Buddhist approaches to health. These six videos, which are intended to be used as introductory teaching materials, are now also being used to provide a thematic organizational structure on the project homepage. There are also a number of other resources for teachers on the website, in the hopes that these may inspire faculty to organize similar ethnographic projects in other cities. 


\section{Project Findings}

In order to ensure students' interactions with interviewees do not cross any ethical lines, we spent a great deal of time in the class on ethnographic methods and ethics. One way that I chose to navigate these issues (which also greatly facilitated the IRB process) is to focus the Jivaka Project squarely on institutions rather than individual people. The project's inclusion criteria required that Buddhist institutions possess a physical building, so we have purposefully not included the many meditation classes, study groups, and other informal sanghas that meet around the city in shared spaces. ${ }^{12}$ One consequence of this choice is that the vast majority of the institutions represented in our project are temples, and these primarily have been founded by Asian American immigrant communities. Matching the demographics of Philadelphia, the majority of these temples are Chinese, Vietnamese, Korean, and Cambodian, but the project also includes examples of Burmese, Japanese, Lao, Mongol/Kalmyk, Taiwanese, and Thai institutions. There are also a smaller number of institutions represented that serve a primarily Caucasian, African American, or mixed demographic - most of those being local branches of major international organizations such as Shambhala, Soka Gakkai, and Won Buddhism. ${ }^{13}$ Surprisingly given Philadelphia's size, nearly every major form of Buddhism in the world is represented in our survey, including all sorts of Theravada, Mahayana, Vajrayana, and non-traditional sectarian affiliations.

Students have documented many health-seeking activities at these diverse locations, including the performance of public and private healing rituals, individual and communal chanting or prayer, and the practice of silent meditations or visualizations. ${ }^{14}$ Within some temple contexts, traditional Asian medical procedures such as acupuncture, herbal medicine, and massage are utilized. We have also documented supportive social interactions among community members that promote mental and physical wellbeing, periodic festivals that feature native foods with health benefits, and sometimes even health fairs where attendees can receive checkups from medical professionals.

These contributions of Buddhist institutions to the American healthcare landscape have never been systematically explored by scholars of Buddhism or American religion. ${ }^{15}$ Nevertheless, our project has clearly shown how central healthcare activities are within the lived religion of Buddhism. This is particularly the case among Asian immigrants and refugees, but judging from what we have learned from the non-Asian institutions in our study, this also seems to hold true for practitioners of other ethnicities and backgrounds. ${ }^{16}$

Scholars and critics have pointed out that mainstream English-language media and academic research have unduly focused on Caucasians, all too often glossing over or forgetting altogether the significant contributions of Asian Americans and other people of color to the story of Buddhism in the U.S. ${ }^{17}$ The Jivaka Project has attempted to push back against this erasure, enhancing the visibility of non-white and non-native-English-speaking Buddhist communities, both within the classroom as well as in the public eye. A priority of the project is specifically to bring more diverse perspectives into our understanding of the connections between Buddhism and healthcare in the U.S. When broaching the topic of health, the popular media has tended to exclusively focus on the practice of mindfulness meditation, which is becoming ever more widespread among affluent white Americans. ${ }^{18}$ Bringing more diverse voices into this conversation opens up the richer world of practices and cultural orientations toward health and healing that are currently flourishing within contemporary American Buddhism, beyond mindfulness. Paying close attention to these intersections has provided a launching-off point for my students to immerse themselves in both the religious and medical pluralism of Philadelphia, while having the opportunity to explore diverse ethnic, cultural, linguistic, and socioeconomic contexts around the city.

\section{Pedagogical Outcomes}

The content covered in my American Buddhism class centers around critical perspectives on immigration, race, and cultural difference, and particularly emphasizes how Buddhist institutions have helped immigrants and refugees to find a home and a voice in American society since the early twentieth century. Students learn about the intersecting 
history of American Buddhism and Asian immigration via our textbook, several documentary films, and other course materials. ${ }^{19}$ However, conducting our ethnographic research in local temples is a major focus of this class.

The pedagogical benefits of this experiment in community-engaged, student-led ethnography are clear. Participating students learn a number of research and creative skills through their experiences interviewing and producing multimedia materials. Their work is inherently collaborative, both in the sense that students visit temples in groups and also in the sense that this is an iterative project that builds from class to class and year to year. The project is also inherently interdisciplinary, involving elements of religious studies, anthropology, public health policy, photojournalism, and documentary filmmaking. The skills students learn are thus immediately transferable to many different fields.

Importantly, involvement in this project has provided the opportunity for students of all backgrounds to gain intimate exposure to Philadelphia's multiethnic and multicultural diversity. They also gain practical, real-world experience with intercultural communication. Through personal interactions with people from diverse backgrounds, students become more knowledgeable of and empathetic toward all kinds of cultural, racial, and socioeconomic difference-which is vitally important for the ethical formation of future global citizens. ${ }^{20}$

The skills and intercultural competencies gained through participation in the project prepare students for future study and employment. For example, one honors student who contributed significantly to the project in its first two years subsequently entered into a master's degree program in public health and quickly was promoted to be part of a research team interviewing inner city families about lead exposure. Presenting alongside me at a conference venue a few years ago, she credited the Jivaka Project with teaching her how to enter into unfamiliar environments, engage in conversation with people from different cultural backgrounds, and navigate any number of linguistic hurdles when gathering public health data.

Beyond preprofessional training, I am also particularly excited about the pedagogical value of this project for international and first-generation Asian American students. Due to the abovementioned demographics of Abington College, it turns out that when my students visit temples, usually at least one person on the team-and sometimes everyone in the group-identifies as belonging to the primary cultural-linguistic affiliation of the temple in question. Many of my students speak Asian languages fluently, have previous personal experience with Buddhism, or at the very least are somewhat familiar with the kinds of temple spaces we are visiting. Like the very first student whose interview of her grandmother inspired the project, students often have family members or acquaintances who attend the very institutions where we are doing our ethnographic work, and they may live in the same neighborhood.

This means that these students are uniquely qualified ethnographers due to their unprecedented degree of access to the local Buddhist community. It also means that the project has given many students the opportunity to bring stories and experiences from their own communities into the classroom and into the project. This dynamic reverses the usual "deficit model" that all too often characterizes the educational experience for English language learners. ${ }^{21}$ Students with non-fluent oral and written communication are too often treated as liabilities in the humanities classroom by faculty who are focused on remediating what are seen as deficits in students' skills. In my class, on the other hand, these same students have come to play an indispensable role as cultural liaisons precisely because of their bilingual and bicultural backgrounds. They are uniquely able to help their monolingual and monocultural classmates navigate temple spaces and to increase their cultural awareness. ${ }^{22}$ In so doing, these students are increasingly recognized as authorities by their peers, and increasingly come to see their own mixed heritage as an asset.

As students become increasingly confident embodying the role of experts in the classroom, the typical power dynamic between students and professor also begins to flip upside down. As the semester progresses, it becomes increasingly clear that I am not 
there to explain "the Buddhist other" to the students from my position of authority at the front of the classroom. ${ }^{23}$ Instead, both the students and I come to see ourselves as engaging in building our mutual understanding of Buddhism from the ground up. We learn together how a Cambodian temple in Center City assists new arrivals to access the American healthcare system, and how the resident monks are helping to address the collective trauma experienced by their community of refugees. ${ }^{24}$ We learn this not by reading about it in a textbook written by a scholarly authority, but instead through impactful student-generated materials that are locally situated in their own communities, and highly relevant to their own lives.

It has been immensely important for students to see their own often-marginalized communities, traditions, and life stories being centered in our semester's intellectual journey in this way. As one Asian American student put it in an email they wrote to me after graduation: "During my [job] interviews, I was asked about my proudest accomplishment and I mentioned the Jivaka Project. Participating in a project that allowed me to explore various medical practices in my community left a significant impact in my academic career and life to this day." This student's meaningful experience is not an accidental byproduct, but very much an intentional outcome of the structure of the class and methodology of the ethnographic project. Like the very first student who placed her grandmother's temple on equal footing and in dialogue with Philadelphia's major hospital-based mindfulness classes, the Jivaka Project provides a structure for students to bring to light and to legitimize their communities' beliefs, practices, and lived experience.

\section{Conclusions}

The Jivaka Project and the class built around it have been a constant source of growth for me, both as a teacher and as a scholar. I cannot count the number of times that I have learned from my students rather than the other way around. Teaching this class (or, should I say, "facilitating" this class) has been an invigorating change of pace from my usual fare. ${ }^{25}$ This project allows me to work with students on a topic that is parallel to my primary research interests, but which has much more immediate connections to their present-day concerns. With issues at the intersection of immigration, healthcare, and religion constantly in the news these days, each new iteration of the class feels exciting and fresh. The class content is always relevant to the times, with obvious implications for healthcare and immigration policymaking. It pushes back against prejudice and xenophobia by increasing empathy for immigrants and refugees. It showcases the rich multiethnic social fabric of contemporary American life at a time when this message has been sorely needed.

Both the student demographic at my institution and our proximity to a major urban center with a diverse population of Asian American Buddhists have been major resources for me in developing this pedagogical experiment. However, I am especially grateful to the Chinese American student who brought her grandmother's religious beliefs and practices to my attention. By doing so, she inspired me to see beyond my own myopic research focus to begin to explore contemporary Buddhist healing right here in Philadelphia. She also inspired me to reinvent my teaching in a way that is much more inclusive and empowering for my students, and more fulfilling for me. I hope that this essay may similarly inspire other faculty to consider learning from our students, to give them a platform by which they may bring their own stories into our academic discourse, and to open up to allowing these interchanges to spark radical transformations in our pedagogical approaches.

Funding: This research was funded by Abington College Undergraduate Research Activities, Penn State Center for Student Engagement, Penn State Schreyer Institute for Teaching Excellence, Penn State Teaching \& Learning with Technology, and American Religious Sounds Project (Ohio University).

Institutional Review Board Statement: The Jivaka Project's study in Philadelphia was deemed exempt from IRB oversight. The research does not meet the definition of a "human subject" because the data being collected is about the temples and not about the individuals. 
Informed Consent Statement: Informed consent was obtained from all subjects involved in the study.

Data Availability Statement: Data from the Jivaka Project is available publicly at www.jivaka.net/ philly.

Conflicts of Interest: The author declares no conflict of interest.

\section{Notes}

1 Some portions of this article are adapted from blog posts first published at https:/ / piercesalguero.medium.com (accessed on 4 June 2021), and some portions are adapted from verbiage on https:/ /www.jivaka.net (accessed on 4 June 2021). I would like to thank Melanie Boston and Angela Jeon-Huh for connecting me with some of the scholarship on teaching and learning cited in this paper. I have also benefitted greatly from conversations with Courtney Bruntz, Kin Cheung, Lan A. Li, Scott Mitchell, and Natalie Quli about some of the pedagogical approaches discussed in this essay. I am also grateful for the resource http: / / teachingbuddhism.net (accessed on 4 June 2021), which follows developments in Buddhist Studies pedagogy. Influential recent publications in that area include Hori et al. (2004) and Lewis and DeAngelis (2017). Other recent highlights include the rising prevalence of panels on pedagogy at the American Academy of Religion since 2018, including the creation of the Buddhist Pedagogy Seminar.

2 I have written about the integration of my courses in Buddhist studies into the general education curriculum in (Salguero 2021).

3 See definition at https:/ / www.aanapisi.net (accessed on 4 June 2021).

4 See definition in Hudzik (2011).

5 See (Sanderson 2008).

6 I do not have permission to publish this student's name, or the name of other students mentioned below, in association with specific contributions or quotes. However, students who were major contributors to the project have been named in note 10 .

7 Since that time, I have summarized the diversity of Buddhism in Philadelphia in an online article: https://religioussounds.osu. edu/blog/buddhism_philadelphia.

8 I am particularly grateful to Ann Gleig, Ira Helderman, Wakoh Shannon Hickey, and Scott Mitchell, who took me under their wings during this period and introduced me to the field of American Buddhism. For background in this field, I particularly recommend (Gleig 2019; Helderman 2019; Hickey 2019; Mitchell and Quli 2015).

9 See details and bibliography about this figure at http:/ / www.jivaka.net/who-is-jivaka/ (accessed on 4 June 2021).

10 Students who participated as group leaders or who otherwise contributed in a major way to the project include Christina Chen, Ashley Cole, Patrick Kim, Meihang Lim, Alex Medina, Vinh Pham, Ryan Rose, Angelina Wu, Jane Yeung, Sinna Zheng, and Paola Xhuli. Additional research assistance and translation was provided by Courtney Bruntz, Somtanuek Chotchoungchatchai, Jennifer Hunter, Sungsim Kim, Hieu Phung, and Emily S. Wu.

11 http:/ / religioussounds.osu.edu (accessed on 4 June 2021).

12 This fact also separates our project from Harvard's Pluralism Project, which has an unreliable and outdated list of Buddhist organizations in Philadelphia.

13 The project has not imposed strong boundaries around the category "Buddhist," and thus has included organizations that scholars have sometimes designated as New Religious Movements instead. As far as this project is concerned, if a group self-identifies as Buddhist, they are included in our project. For discussion of some of these issues related in the case of Won Buddhism, see (Pye 2002; Baker 2012).

14 In an unexpected crossover from my pedagogy to my scholarly publication, after the project had been up and running for four years, I published an article in Religions detailing some of these health-seeking activities, as well as their implications for the study of American Buddhism. See (Salguero 2019a), and see also excerpts of interviews in (Salguero 2019b, pp. 317-26).

15 Previous studies include (Wu 2002; Numrich 2005; Cheung and Salguero 2019), but these have a far more limited scope.

16 The main findings of the research project are summarized in (Salguero 2019a). There, I argued that neighborhood demographics and other social factors play as important a role as culture and sectarian affiliation in shaping the kinds of healthcare activities temples are involved in.

17 See (Hickey 2010, 2019; Cheah 2011; Han 2021). See also the influential blogs https:/ / www.lionsroar.com/weve-been-here-allalong and https:/ / tricycle.org/trikedaily/asian-american-erasure-buddhism (accessed on 30 April 2021).

18 See discussion in (Wilson 2014; Hickey 2019, pp. 137-218).

19 Despite the general critique of textbooks for American Buddhism in (Berkwitz 2004), I have found (Mitchell 2016) to be an excellent textbook for my class. Films I find particularly engaging for students are Ric Burns' Exclusion Act (2017) for historical background about racism against Asian immigrants in the U.S., Bill Ferehawk and Dylan Robertson's Aloha Buddha (2011) for early twentieth century challenges facing Japanese American Buddhists in Hawai'I, and Kentaro Sugao's Streams of Light-Shin Buddhism in America (2013) which picks up where Aloha Buddha leaves off and follows the transformation of Jodo Shinshu into a distinctly American form of twenty-first century Buddhism.

20 The benefits of intercultural pedagogy are discussed in (Mikk and Steglitz 2017; Lee 2017).

21 See discussion in (Ryan 2011).

22 The pedagogical benefits of mixing international and domestic students together in the classroom are discussed in (Yefanova et al. 2017; Luo and Jamieson-Drake 2013; Amos and Rehorst 2018). 
Because I am focused on pedagogy, I have
analysis is available in (Salguero 2019a).

25 On "intercultural facilitation" as a pedagogical method, see (Mikk and Bjarnadottir 2017).

\section{References}

Amos, Yukari Takimoto, and Nicole Rehorst. 2018. Making Interactions between Domestic and International Students Meaningful. Journal of International Students 8: 1346-54. [CrossRef]

Baker, Don. 2012. Constructing Korea's Won Buddhism as a New Religion: Self-differentiation and Inter-religious Dialogue. International Journal for the Study of New Religions 3: 47-70. [CrossRef]

Berkwitz, Stephen C. 2004. Conceptions and Misconceptions about 'Western Buddhism': Issues and Approaches for the Classroom. Teaching Theology \& Religion 7: 141-52.

Cheah, Joseph. 2011. Race and Religion in American Buddhism: White Supremacy and Immigrant Adaptation. New York: Oxford University Press.

Cheung, Kin, and C. Pierce Salguero. 2019. Interview with a Contemporary Chinese American Healer. In Buddhism and Medicine: An Anthology of Modern and Contemporary Sources. Edited by C. Pierce Salguero. New York: Columbia University Press, pp. $241-51$.

Gleig, Ann. 2019. American Dharma: Buddhism Beyond Modernity. New Have: Yale University Press.

Han, Chenxing. 2021. Be the Refuge: Raising the Voices of Asian American Buddhists. Berkeley: North Atlantic Books.

Helderman, Ira. 2019. Prescribing the Dharma: Psychotherapists, Buddhist Traditions, and Defining Religion. Chapel Hill: University of North Carolina Press.

Hickey, Wakoh Shannon. 2010. Two Buddhisms, Three Buddhisms, and Racism. Journal of Global Buddhism 11: 1-25.

Hickey, Wakoh Shannon. 2019. Mind Cure: How Meditation Became Medicine. New York: Oxford University Press.

Hori, Victor Sōgen, Richard P. Hayes, and J. Mark Shields, eds. 2004. Teaching Buddhism in the West: From the Wheel to the Web. New York: Routledge.

Hudzik, John K. 2011. Comprehensive Internationalization: From Concept to Action. Washington, DC: NAFSA.

Lee, Amy. 2017. Teaching Interculturally: A Framework for Integrating Disciplinary Knowledge and Intercultural Development. Sterling: Stylus.

Lewis, Todd, and Gary DeAngelis. 2017. Teaching Buddhism: New Insights on Understanding and Presenting the Traditions. New York: Oxford University Press.

Luo, Jiali, and David Jamieson-Drake. 2013. Examining the Educational Benefits of Interacting with International Students. Journal of International Students 3: 85-101. [CrossRef]

Mikk, Barbara Kappler, and Thorunn Bjarnadottir. 2017. Intercultural Facilitation. In Learning across Cultures: Locally and Globally, 3rd ed. Edited by Barbara Kappler Mikk and Inge Ellen Steglitz. Sterling: Stylus \& NAFSA, pp. 139-66.

Mikk, Barbara Kappler, and Inge Ellen Steglitz, eds. 2017. Learning across Cultures: Locally and Globally, 3rd ed. Sterling: Stylus \& NAFSA.

Mitchell, Scott A. 2016. Buddhism in America: Global Religion, Local Contexts. London: Bloomsbury.

Mitchell, Scott A., and Natalie E. F. Quli. 2015. Buddhism beyond Borders: New Perspectives on Buddhism in the United States. Albany: SUNY Press.

Numrich, Paul David. 2005. Complementary and Alternative Medicine in America's 'Two Buddhisms'. In Religion and Healing in America. Edited by Linda L. Barnes and Susan S. Sered. Oxford and New York: Oxford University Press.

Pye, Michael. 2002. Won Buddhism as a Korean New Religion. Numen 49: 113-41. [CrossRef]

Quli, Natalie F. 2009. Western Self, Asian Other: Modernity, Authenticity, and Nostalgia for 'Tradition' in Buddhist Studies. Journal of Buddhist Ethics 16. Available online: http:/ / blogs.dickinson.edu/buddhistethics/files/2010/05/quli-article.pdf (accessed on 4 June 2021).

Ryan, Janette. 2011. Teaching and learning for international students: Towards a transcultural approach. Teachers and Teaching 17: 631-48. [CrossRef]

Salguero, C. Pierce. 2019a. Varieties of Buddhist Healing in Multiethnic Philadelphia. Religions 10: 48. [CrossRef]

Salguero, C. Pierce. 2019b. Buddhism \& Medicine: An Anthology of Modern and Contemporary Sources. New York: Columbia University Press.

Salguero, C. Pierce. 2021. The Role of Buddhist Studies in Fostering Metadisciplinary Conversations and Improving Pedagogical Collaborations. Religions 12: 1. [CrossRef]

Sanderson, Gavin. 2008. A foundation for the internationalization of the academic self. Journal of Studies in International Education 12: 276-307. [CrossRef]

Wilson, Jeff. 2014. Mindful America: The Mutual Transformation of Buddhist Meditation and American Culture. New York: Oxford University Press.

Wu, Hongyu. 2002. Buddhism, Health, and Healing in a Chinese Community. Available online: http://pluralism.org/wp-content/ uploads/2015/08/Wu.pdf (accessed on 11 January 2019).

Yefanova, Diana N., Mary Lynn Montgomery, Gayle A. Woodruff, Christopher J. Johnstone, and Barbara Kappler. 2017. Instructional Practices Facilitating Cross-National Interactions in the Undergraduate Classroom. Journal of International Students 7: 786-805. [CrossRef] 